\title{
Clinical Investigations of Percutaneous Vertebroplasty Combined with Intensity-modulated Radiotherapy for Patients with Spinal Metastases
}

\author{
Chen $\mathrm{X}^{1 \#}$, Xie XQ" ${ }^{2 \#}$, Li WM" ${ }^{3}$, Liao $\mathrm{ZY}^{1 *}$, Wu DB ${ }^{4}$ \\ and Wang $F^{1 *}$ \\ ${ }^{1}$ Department of Medical Oncology, Sichuan University, \\ China \\ ${ }^{2}$ Department of Critical Care Medicine, Sichuan \\ University, China \\ ${ }^{3}$ Sichuan University, West China Hospital, PR China \\ ${ }^{4}$ Cancer Hospital, Ansteel Group Hospital, PR China \\ \#These authors contributed equally to this article \\ *Corresponding author: Feng Wang, Department of \\ Medical Oncology, Cancer Center, West China Hospital, \\ West China Medical School, Sichuan University, No. 37, \\ Guo Xue Xiang, Chengdu 610041, Sichuan Province, \\ China
}

Zheng Ying Liao, Department of Critical Care Medicine, West China Hospital, Sichuan University, Chengdu 610041, Sichuan Province, China

Received: March 15, 2021; Accepted: March 29, 2021; Published: April 05, 2021

\section{Introduction}

Spinal metastasis is a common complication of cancer. It can cause severe spinal pain, pathological vertebral fractures, spinal cord compression, paraplegia and so on. They all lead a poor prognosis [1]. Now days Percutaneous Vertebroplasty (PVP) and radiotherapy are the most used in ensuring relief from discomfort at the end of life expectancy [2]. Radiotherapy (RT) can provide successful palliation of painful bone metastasis in 50-80 \% of patients [3]. IMRT makes it possible to deliver optimal radiation doses safely [4]. PVP is a recently developed treatment for spinal metastases. It appeared to be an alternative method to treat painful spine metastases [5]. But few studies report on the clinical observation of PVP combined with IMRT in the treatment of metastatic lesions of the spine. In this article, feasibility and clinical effects were discussed in the patients with spinal metastases who were treated with percutaneous vertebroplasty combined with intensity-modulated radiotherapy.

\section{Material and Method}

\section{Patients}

It is a retrospective study. We collected 7 patients from West China Hospital (2010-2012), and record the medical characters of these patients. They were all diagnosed as malignant tumor with spinal metastases. The primary tumor sites are laryngeal, nasopharyngeal, liver, and lung. Two of the patients are unknown primary focal. The mean age of the study participants was 55.8 years (range: $32-68$ years). PVP combined with IMRT are used in these spinal metastases sites. The most commonly involved spine levels are between C2 and L3. Clinical and pathological characteristics of the cases are showed in
Table 1.

\section{Treatment procedure}

All patients underwent, computed tomograph, magnetic resonance imaging, or bone scanning for evaluation of metastasis lesions. The indication for PVP was an unstable or painful metastatic tumor. Specific methods for PVP: cervical puncture in the supine position, thoracolumbar prone position. Regular disinfection shop towels, local infiltration anesthesia. The anterior lateral approach is commonly used in cervical spine surgery, and the thoracic and lumbar spine can be operated by pedicle of vertebral arch or the posterior lateral approach under X-raw. $5-10 \mathrm{~cm}$ bone cement were used in one vertebral body. Once the bone cement is found to be leaking into the spinal canal, intervertebral foramen, or venous plexus, the injection should be stopped immediately. The IMRT was performed in the vertebral metastasis area after patients undergoing PVP for approximately 30 days using an $6 \mathrm{MV}$-X linear at a dose of

Table 1: Patient characteristics, PVP and IMRT.
\begin{tabular}{|c|c|c|c|c|c|c|}
\hline $\begin{array}{c}\text { Case } \\
\text { No. }\end{array}$ & Age & Sex & Primary Cancer & $\begin{array}{c}\text { PVP } \\
\text { Levels }\end{array}$ & $\begin{array}{c}\text { Follow-up } \\
\text { (mos) }\end{array}$ & Comment \\
\hline 1 & 66 & M & $\begin{array}{c}\text { Laryngeal cancer } \\
\text { C2-3 }\end{array}$ & 40 & dead \\
\hline 2 & 45 & M & $\begin{array}{c}\text { Nasopharyngeal } \\
\text { cancer }\end{array}$ & C5 & 73 & alive \\
\hline 3 & 68 & F & $\begin{array}{c}\text { Metastais of unknown } \\
\text { origin }\end{array}$ & L1 & 59 & alive \\
\hline 4 & 65 & F & Liver Cancer & L1-3 & 3 & dead \\
\hline 5 & 32 & M & $\begin{array}{c}\text { Metastais of unknown } \\
\text { origin }\end{array}$ & C2-3 & 20 & dead \\
\hline 6 & 50 & M & Lung Cancer & L1-2 & 46 & alive \\
\hline 7 & 65 & F & Lung Cancer & T L & 24 & dead \\
\hline
\end{tabular}

Austin J Nucl Med Radiother - Volume 6 Issue 1 - 2021 Submit your Manuscript | www.austinpublishinggroup.com Chen et al. (c) All rights are reserved
Citation: Chen X, Xie XQ, Li WM, Liao ZY, Wu DB and Wang F. Clinical Investigations of Percutaneous Vertebroplasty Combined with Intensity-modulated Radiotherapy for Patients with Spinal Metastases. Austin J Nucl Med Radiother. 2021; 6(1): 1025. 


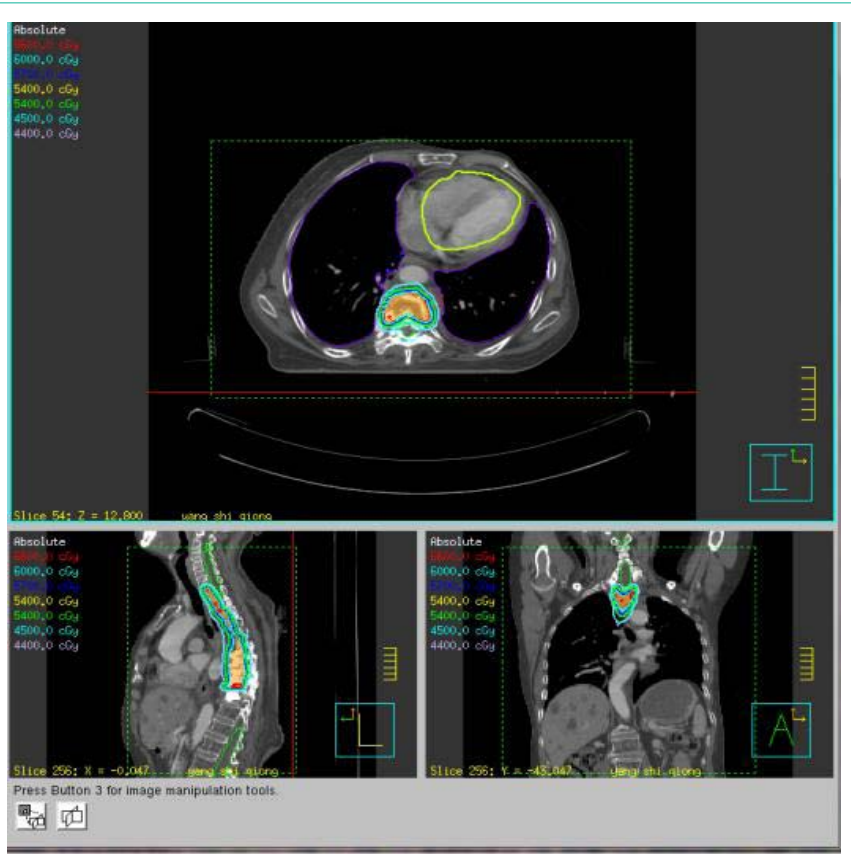

Figure 1: Distribution of IMRT plan.

40-60Gy.The Gross Tumor Volume (GTV) of a tumor was defined as the volume of gross visible tumor plus margins of approximately $2 \mathrm{~mm}$ with a total dose 40-60Gy . The Clinical Tumor Volume (CTV) was defined as the GTV plus a margin (35-50Gy). The planning target volume was defined as the CTV plus $2 \mathrm{~mm}$ margins (30-50Gy) Distribution of intensity-modulated radiation therapy plan was showed in Figure 1.

\section{Results}

All the patients complete the treatment procedures. 13 vertebral bodies were punctured, and the success rate of PVP puncture is $100 \%$.There are no severe complications were observed, such as bone marrow mud leakage, Spinal cord injury, local pain and so on. 7 patients all received IMRT (40-60Gy/20-30f). The process is successful, and the patients can endure the exposure during the position and limb braking requirements. Cancer pain were relieved in all the patients in $6-72 \mathrm{~h}$ after PVP. The total effective rate is $100 \%$. No pain or fracture were found after PVP combined with IMRT. Three patients are still alive until now.

\section{Discussion}

Spinal metastases are becoming increasingly common because of the rising incidence of cancer and the improved survival of cancer patients [6,7]. At least $40 \%$ of patients with advanced cancer will have spinal involvement during the course of their disease [16]. The treatment of painful vertebral metastases is a major target $[10,11]$. The maintenance of spinal stability, reduction of pain, and prevention of neurological deterioration can affect a patient's quality of life. The treatment methods of spinal metastatic tumors include: double phosphate drugs, analgesic drugs, chemotherapy (including hormone therapy), radiation therapy, percutaneous vertebral angioplasty, percutaneous radiofrequency ablation, decompression surgery therapy, radionuclide therapy, etc. Now days radiation therapy and
PVP are commonly used for spinal metastases. Under the treatment of PVP, $80 \%$ patients can achieve significant pain relief within 1 hours, and the analgesic effect is more than $75 \%$ [13]. Radiotherapy (RT) can provide successful palliation of painful bone metastasis in 50-80\% of patients [14]. While IMRT are particularly well suited for the treatment of spinal bone metastases when they are localized or require re-irradiation, and may provide superior tumor control [15].

There are article compared the efficacy of External Radiotherapy (ERT) and PVP for spinal metastasis, and showed that ERT combined with PVP achieved pain remission in $84.8 \%$ of the patients, which was higher than ERT (72.5\%) or PVP (76.3\%) alone [12]. Yi Li, et al has evaluate the safety and efficacy of PVP combined with IMRT for vertebrae metastatic lesions of patients with Non-Small-Cell Lung Cancer (NSCLC), They used the Visual Analog Scale (VAS) to assess the degree of pain, the mean VAS score and the activities of daily living, evaluation showed that the patients had a significantly high life quality after the combined approach $(\mathrm{P}<0.05)$ [8]. JEE-SOO JANG et al indicated that the mean VAS pain score was reduced from 8.2 to 3 under the treatment of PVP combined with RT [9]. In our series, all the patients got pain relief and no pain or fracture were found after PVP combined with IMRT. PVP combined with IMRT seems to be an effective and feasible means to improve the quality of life of patients with tumor vertebral metastasis.

\section{Conclusion}

Percutaneous vertebroplasty combined with intensity-modulated radiotherapy can provide pain relief and stability for cancer patients with spinal metastases.

\section{References}

1. Bartels RH, van der Linden YM, van der Graaf WT. Spinal extradural metastasis: review of current treatment options. CA Cancer J Clin. 2008; 58: 245-259.

2. Huang M, Hong ZHU, Taiguo LIU, Dandan CUI, Huang Y. Comparison of external radiotherapy and percutaneous vertebroplasty for spinal metastasis. Asia-Pacifi C Journal of Clinical Oncology. 2016; 12: e201-e208.

3. Chow E, Harris K, Fan G, Tsao M, Sze WM. Palliative radiotherapy trials for bone metastases: a systematic review. J Clin Oncol. 2007; 25:1423-1436.

4. Ejima Y, Matsuo Y, Sasaki R. The current status and future of radiotherapy for spinal bone metastases. J Orthop Sci. 2015; 20: 585-592.

5. Xie P, Zhao Y, Li G. Efficacy of percutaneous vertebroplasty in patients with painful vertebral metastases: A retrospective study in 47 cases. Clin Neurol Neurosurg. 2015; 138: 157-161.

6. Lo SS, Sahgal A, Wang JZ, Mayr NA, Sloan A, Mendel E, et al. Stereotactic body radiation therapy for spinal metastases. Discov Med 2010; 9: 289-296.

7. Sheehan JP, Jagannathan J. Review of spinal radiosurgery: a minimally invasive approach for the treatment of spinal and paraspinal metastases. Neurosurg Focus. 2008; 25: E18.

8. Li Y, Qing Y, Zhang Z, Li M, Xie J, Wang G, et al. Clinical efficacy of percutaneous vertebroplasty combined with intensity-modulated radiotherapy for spinal metastases in patients with NSCLC. Onco Targets Ther. 2015; 8: 2139-2145.

9. Jang JS, Lee SH. Efficacy of percutaneous vertebroplasty combined with radiotherapy in osteolytic metastatic spinal tumors. J Neurosurg Spine. 2005: 2: $243-248$.

10. Lo SS, Sahgal A, Wang JZ, Mayr NA, Sloan A, Mendel E, et al. Stereotactic body radiation therapy for spinal metastases. Discov Med. 2010; 9: 289-296.

11. Sheehan JP, Jagannathan J. Review of spinal radiosurgery: a minimally 
invasive approach for the treatment of spinal and paraspinal metastases. Neurosurg Focus 2008; 25: E18.

12. Huang M, Hong ZHU, Taiguo LIU, Dandan CUI, Huang Y. Comparison of external radiotherapy and percutaneous vertebroplasty for spinal metastasis. Asia-Pacifi c Journal of Clinical Oncology. 2016; 12: e201-e208.

13. Barr JD, Barr MS, Lerriey TJ, McCann RM. Percutaneous vertebroplasty for pain relief and spinal stabilization. Spine. 2000; 25: 923-928.
14. Chow E, Harris K, Fan G, Tsao M, Sze WM. Palliative radiotherapy trials for bone metastases: a systematic review. J Clin Oncol. 2007; 25:1423-1436.

15. Ejima $Y$, Matsuo $Y$, Sasaki R. The current status and future of radiotherapy for spinal bone metastases. J Orthop Sci. 2015; 20: 585-592.

16. Bohm $\mathrm{P}$, Huber J. The surgical treatment of bony metastases of the spine and limbs. J Bone Joint Surg Br. 2002; 84: 521-529. 